\title{
Effects of introversion-extraversion on continuous recognition memory
}

\author{
CHRIS R. GILLESPIE and MICHAEL W. EYSENCK \\ Birkbeck College, University of London, London WCIE 7HX, England
}

\begin{abstract}
Introverted and extraverted subjects performed a continuous recognition memory task, indicating on a 5-point scale whether each item was new or old. Analysis of the data by signal detection theory measures indicated that introverts adopted a more stringent response criterion than extraverts, but that there was no effect of introversion-extraversion on sensitivity or $\mathrm{d}^{\prime}$. Some of the theoretical implications of these and other findings are discussed. Since selfreported arousal levels were unrelated to performance, it may be inappropriate to interpret the effects of introversion-extraversion in terms of differences in chronic arousal level between introverts and extraverts.
\end{abstract}

Eysenck (1976, in press) has reviewed the literature on the effects of individual differences in introversionextraversion on memory. One of the most consistent findings is that extraverts exhibit memory performance superior to that of introverts at relatively short retention intervals up to several minutes; this tendency is greater when the learning task is relatively difficult or involves response competition.

While this memorial superiority of extraverts may reflect a genuine increase in the quality of stored information, it may also be due, at least in part, to differences in response criteria between introverts and extraverts. In the vigilance paradigm, signal-detection theory analysis has indicated that extraverts adopt consistently less stringent criteria for response than introverts (see Eysenck, in press, for a review); this may be related to the generally greater cautiousness of introverts (Cameron \& Myers, 1966). As regards work on learning and memory, there is at least one suggestive finding. McLaughlin and Kary (1972) presented introverted and extraverted subjects with a series of free recall lists, each followed by an immediate test for recall or recognition. On the recognition tests, extraverts made more correct responses and more errors than introverts; this pattern of results is consistent with the notion that the relatively poor memory performance of introverts is partially attributable to their elevated threshold for response.

The main interest in this study was to compare the memory performance of introverts and extraverts by means of signal detection theory analysis (Green \& Swets, 1966), which provides separate measures of sensitivity or discrimination $\left(\mathrm{d}^{\prime}\right)$ and of response criterion. If consistent differences were found between introverts

C. R. Gillespie is now at Saint Crispin Hospital, Northampton, England. Requests for reprints should be addressed to Michael W. Eysenck, Department of Psychology, Birkbeck College, University of London, Malet Street, London WC1E 7HX, England. and extraverts in response criterion, this would have important implications for the interpretation of previous studies. The task used was one of continuous recognition memory, on which Donaldson and Murdock (1968) found progressive decrements in response criterion over time.

As was pointed out by Eysenck (1976, in press), interpretations of the effects of introversion-extraversion on performance have commonly assumed that introverts are chronically more aroused than extraverts. While there is some empirical support for this assumption, the evidence is rather equivocal (Gale, 1973). In this study, an attempt was made to obtain some relevant evidence by measuring both chronic arousal level (introversionextraversion) and transient arousal level (self-reported general activation). The measure of general activation was obtained from Thayer's Activation-Deactivation Adjective Check List, which is an objective self-report measure of transient levels of activation. Thayer (1967) found that the general activation scale correlated approximately +.6 to +.7 with a physiological index representing the pooled data from various physiological measures. In previous studies on the effects of introversionextraversion on memory, the emphasis has been strongly on arousal in the sense of a characteristic, semipermanent aspect of individual differences; however, it is clear that the subject's transient level of arousal within the experimental situation should also be considered.

\section{METHOD}

\section{Subjects}

There were 28 subjects, who were all pupils at various schools in Hertfordshire, England, within the 16- to 18-year age range. They were divided into four equal-sized groups on the basis of their scores on the extraversion scale of the Eysenck Personality Inventory (Form A) and the general activation scale of the Activation-Deactivation Adjective Check List (Thayer, 1967). The original sample of 76 subjects was reduced by excluding all those who, on the Eysenck Personality Inventory, scored 11 or 12 on the extraversion scale, scored above 14 on the neuroticism 
scale, or scored above 4 on the "lie" scale. For the lowextraversion/low-activation group, the mean extraversion and activation scores were 8.29 and 6.14 , respectively; for the lowextraversion/high-activation group, the mean scores were 6.71 and 15.04 ; for the highextraversion/low-activation group, the means were 15.57 and 7.00 ; and for the highextraversion/ high-activation group, the means were 17.86 and 15.57 .

\section{Materials and Design}

The experimental session started with the administration of the Eysenck Personality Inventory and the Thayer ActivationDeactivation Adjective Check List. There then followed the visual presentation of 168 three-digit numbers, presented by Kodak Carousel slide projector at a rate of one slide every $7 \mathrm{sec}$. Each number appeared twice in the sequence of numbers, with a repetition lag of zero, three, six, or nine intervening items. The sequence of numbers was selected randomly from the set of all three-digit numbers, except that those with a repeated digit or an ascending (e.g., 237) or descending (e.g., 732) sequence were excluded. A Latin square design ensured that there were no sequence effects across trials.

The slides were organized so that there were five blocks of 32 numbers each between the 5 th and 164th slides. Each block consisted of 16 numbers appearing for the first time (new items) and 16 numbers appearing for the second time (old items). Of the 16 old items, there were 4 at each of the possible lags. Thus the five blocks were comparable in terms of the a priori probability of occurrence of an old item and the frequency of the different lags.

As each number was presented, subjects decided whether or not the number was an old number (or signal) on a 5-point scale running from "maximum certainty that the signal was present," through "fairly certain the signal was present," "guess the signal was not present," and "fairly certain the signal was not present," to "certain the signal was not present."

\section{RESULTS}

Each subject's response data from the five blocks were analyzed by means of signal detection theory analysis. The measures of observed sensitivity, or recognition $\left(d^{\prime}\right)$, were obtained by computer program analysis of hits and false alarm rates. The response criterion was calculated using tables for each hit rate/false alarm rate ratio, and the two arbitrary cutoffs (severe and lax) provided the values required for analysis.

The data for sensitivity, or $\mathrm{d}^{\prime}$, were analyzed by means of a three-way analysis of variance comprising the two between-subjects factors of introversion-extraversion and general activation and the one within-subjects factor of blocks. Although there was a tendency for highly activated extraverts to have greater sensitivity of $d^{\prime}$ than any other group of subjects and the triple interaction approached significance, there were not significant main effects or interactions. The conventional .05 level of statistical significance is used throughout.

The response criterion data were analyzed by means of a four-way analysis of variance comprising the two between-subjects factors of introversion-extraversion and general activation and the two within-subjects factors of criterion strictness (severe between the two most stringent scale points) and blocks. The summary data are given in Table 1.
Table 1

Response Criterion (Strict, Lax) as a Function of Introversion-Extraversion, General Activation (High, Low), and Blocks

\begin{tabular}{|c|c|c|c|c|c|c|c|c|}
\hline \multirow[b]{3}{*}{ Block } & \multicolumn{4}{|c|}{ Introverts } & \multicolumn{4}{|c|}{ Extraverts } \\
\hline & \multicolumn{2}{|c|}{ High } & \multicolumn{2}{|c|}{ Low } & \multicolumn{2}{|c|}{ High } & \multicolumn{2}{|c|}{ Low } \\
\hline & Strict & Lax & Strict & Lax & Strict & Lax & Strict & Lax \\
\hline 1 & 2.13 & .21 & 2.15 & .29 & 1.16 & .23 & 1.34 & .22 \\
\hline 2 & .99 & .32 & 1.68 & .12 & .87 & .11 & .93 & .46 \\
\hline 3 & .89 & .07 & 1.48 & .18 & .57 & .05 & .84 & .13 \\
\hline 4 & .78 & .17 & 1.34 & .08 & .62 & .07 & .82 & .15 \\
\hline 5 & 1.05 & .14 & 1.33 & .21 & .51 & .11 & .80 & .16 \\
\hline
\end{tabular}

In line with the continuous recognition memory study of Donaldson and Murdock (1968), there was a continuous and progressive reduction in response criteria across blocks. The main effect of blocks was highly significant $[F(4,96)=10.44, \mathrm{MSe}=.20]$. However, this main effect must be interpreted in light of the significant interaction between blocks and response criterion strictness $[\mathrm{F}(4,96)=6.75, \mathrm{MSe}=.17]$. In this interaction, there was a substantial effect of blocks on the response criterion at the strict criterion, but there was no effect of blocks at the lax criterion.

The remaining significant results involved the personality dimension of introversion-extraversion. In general, introverts adopted more cautious response criteria than extraverts, and this was reflected in a marginally significant main effect of introversion-extraversion $[F(1,24)=$ $4.07, \mathrm{MSe}=1.28 \mathrm{]}$. There was also an interaction between introversion-extraversion and criterion strictness $[\mathrm{F}(1,24)=4.44, \mathrm{MSe}=1.07]$. Analysis of the simple main effects indicated that there was no effect of introversion-extraversion at the low cutoff $[\mathrm{F}(1,48)<1]$; however, introverts adopted a much higher response criterion than extraverts at the strict cutoff $[\mathrm{F}(1,48)=$ $8.44, \mathrm{MSe}=1.18]$. None of the main effects or interactions involving transient levels of general activation was significant.

\section{DISCUSSION}

Performance on the continuous recognition memory task manifested an interesting difference in trend between the two signal detection theory measures: Whereas $\mathrm{d}^{\prime}$ remained constant over blocks, there was a progressive reduction in criterion at the strict criterion. This replicates the findings of Donaldson and Murdock (1968) in a very similar task, and it demonstrates the value of separating different components of task performance. It is unclear why the response criterion should decrease. However it may be relevant that subjects were not informed in the initial instructions of the probability that any number would be an old item. If this probability is underestimated at first, and if subjects engage in probability matching, then the obtained criterion shift would be expected. Obviously, this is only one of several possible interpretations.

The findings of most theoretical interest concerned the effects of individual differences in introversion-xtraversion on sensitivity and the response criterion. There was a nonsignificant 
effect of introversion-extraversion on $\mathrm{d}^{\prime}$, but introverts had a higher criterion for response than extraverts at the stricter response criterion. The latter finding is consistent with the results from several vigilance studies (see Eysenck, in press), and it is also in line with the notion that introverts are generally more cautious than extraverts. The nonequivalence of the effects of introversionextraversion on the two measures of signal detection theory illustrates the value of distinguishing between sensitivity and cautiousness of responding. It is possible that the memorial superiority of extraverts to introverts at relatively short retention intervals reported previously in the literature (see Eysenck, 1976, for a review) was due to an unrecognized influence of introversion-extraversion on decision processes rather than on memory per se. The major disadvantage of the retention measures utilized in previous studies is that they represent a complex amalgam of quality of stored information and cautiousness of responding.

What factors are responsible for the greater response cautiousness of introverts? While our data are by no means conclusive, they do suggest that interpretations based on putative differences between introverts and extraverts in chronic arousal level may be misplaced. The reason for this is that self-reported arousal within the experimental situation did not affect the cautiousness of responding, whether as a main effect or in interaction with other factors.

The search for a more fruitful theoretical approach may start from the typical finding (Green \& Swets, 1966) that response criteria are affected by the gains or rewards associated with hits and the costs or punishments associated with false alarms. As Gray (1972) has indicated, "We may regard the dimension of introversion extraversion as a dimension of susceptibility to punishment and non-reward: the greater the degree of introversion, the greater is this susceptibility" (p. 194). If introverts emphasize the costs associated with false alarms to a greater extent than extraverts, this would explain the greater response caution of introverts. This hypothesis could be investigated further by experimentally manipulating the costs and gains associated with different patterns of responding.

\section{REFERENCES}

Cameron, B., \& Myers, J. L. Some personality correlates of risk taking. Journal of General Psychology, 1966, 74, 51-60.

Donaldson, W., \& Murdock, B. B. Criterion change in continuous recognition memory. Journal of Experimental Psychology, 1968, 76, 325-330.

EySENCK, M. W. Extraversion, verbal learning, and memory. Psychological Bulletin, 1976, 83, 75-90.

EysEnCK, M. W. Personality, learning and memory. In H. J. Eysenck (Ed.), A model for personality. London: Springer, in press.

GaLE, A. The psychophysiology of individual differences: Studies of extraversion and the EEG. In P. Kline (Ed.), New approaches in psychological measurement. London: Wiley, 1973.

Gray, J. A. The psychophysiological nature of introversionextraversion: A modification of Eysenck's theory. In V. D. Nebylitsyn \& J. A. Gray (Eds.), Biological bases of individual behaviour. London: Academic Press, 1972.

Green, D. M., \& Swets, J. A. Signal detection theory and psychophysics. London: Wiley, 1966.

McLaughlin, R. J., \& Kary, S. K. Amnesic effects in free recall with introverts and extraverts. Psychonomic Science, 1972, 29, 250-252.

ThAYER, R. E. Measurement of activation through self-report. Psychological Reports, 1967, 20, 663-678.

(Received for publication January 13, 1980.) 